\title{
Effects of exercise preconditioning on intestinal ischemia- -reperfusion injury
}

\author{
Gokbel $\mathrm{H}^{1}, \mathrm{Oz} \mathrm{M}{ }^{1}$, Okudan $\mathrm{N}^{1}$, Belviranli $\mathrm{M}^{1}$, Esen $\mathrm{H}^{2}$ \\ Department of Physiology, Faculty of Medicine, University of Selçuk, 42075, Selcuklu, Konya, Turkey. \\ ozmhmt@gmail.com
}

\begin{abstract}
Background: To investigate the effects of exercise preconditioning on oxidative injury in the intestinal tissue of rats.

Methods: Sixty male Wistar rats were randomly divided into six groups as sham $(n=10)$, ischemia-reperfusion $(n=10)$, exercise $(n=10)$, exercise plus ischemia-reperfusion $(n=10)$, ischemic preconditioning $(n=10)$, and ischemic preconditioning plus ischemia-reperfusion groups $(n=10)$. Tissue levels of malondialdehyde and activities of myeloperoxidase and superoxide dismutase, and serum levels of tumor necrosis factor-alpha and interleukin-6 were measured. Intestinal tissue histopathology was also evaluated by light microscopy.

Results: Tumor necrosis factor-alpha concentrations significantly decreased in the exercise group compared to the sham group $(p<0.05)$. Myeloperoxidase activity significantly increased and superoxide dismutase activity significantly decreased in ischemia-reperfusion group compared to the sham group $(p<0.05)$. Superoxide dismutase activity in the ischemic preconditioning and ischemic preconditioning plus ischemia-reperfusion groups were significantly higher compared to the ischemia-reperfusion and exercise groups $(p<0.05)$. Histopathologically, intestinal injury significantly attenuated in the exercise plus ischemia-reperfusion group compared to the ischemia-reperfusion group.

Conclusions: The results of the present study indicate that exercise training seems to have a protective role against intestinal ischemia-reperfusion injury (Tab. 3, Fig. 1, Ref. 35). Text in PDF www.elis.sk.

Key words: intestinal ischemia-reperfusion, exercise preconditioning, oxidative status.
\end{abstract}

Intestinal ischemia-reperfusion (I/R) injury is a serious condition caused by surgical interventions such as abdominal aortic surgery and transplantation of intestine or conditions such as necrotizing enterocolitis, intestinal mesenteric vascular ischemia, septic shock and severe trauma (1). I/R leads to the release of reactive nitrogen and oxygen species such as superoxide anion, hydroxyl radical, hydrogen peroxide and peroxynitrite (2). It is well known that lipid peroxidation due to reactive oxygen species is an important factor leading to damage of intestinal I/R (3). In addition, ischemia induced by intestinal damage worsens as a result of oxygen re-input occurring during reperfusion of the ischemic tissue $(4,5)$ ). Paradoxically, re-sustaining the blood flow causes greater damage, i.e. reperfusion injury. Many components of the cells are exposed to free radical attack in a large number of clinical conditions including $\mathrm{I} / \mathrm{R}$, and it is known that toxic oxygen metabolites are the most common etiologic factors of tissue damage (6). Intestinal $\mathrm{I} / \mathrm{R}$ also activates the neutrophils. Activated neutrophils increase ischemic damage causing a release of proteolytic enzymes

${ }^{1}$ Department of Physiology, Faculty of Medicine, University of Selcuk, Selcuklu, Konya, Turkey, and ${ }^{2}$ Department of Pathology, Meram Faculty of Medicine, University of Necmettin Erbakan, Meram, Konya, Turkey

Address for correspondence: M. Oz, Department of Physiology, Faculty of Medicine, University of Selcuk, 42075, Selcuklu, Konya, Turkey. Phone: +903322237111, Fax: +903322237124

Acknowledgement: This study has been supported by the Research Foundation of the Selcuk University, Konya Turkey (09-1102). and cytotoxic free radicals (7). It is believed that proinflammatory cytokines such as tumor necrosis factor- $\alpha(\mathrm{TNF}-\alpha)$, interleukin (IL) -6 , IL-1 and oxygen-derived free radicals are important mediators during intestinal I/R (8).

In general, regular physical activity decreases the incidence of stroke and risk factors for cardiovascular disease such as insulin resistance, obesity, hypercholesterolemia, and hypertension (9-12). It has been observed that endurance exercise causes an increase in ventricular antioxidant levels and decrease in lipid peroxidation, and protects myocardium against myocardial $\mathrm{I} / \mathrm{R}$ injury in rats $(13,14)$. Taken together, these changes reinforce myocardial protection against damage by I/R. The effects of physical activity on gastrointestinal organs are interesting. Moderate exercise may reduce the risk of colon cancer and formation of cholelithiasis, and speed up the passage through colon which may be part of the treatment of constipation and reduction of occurrence of colonic diverticular disease, whereas heavy exercise leads to the observation of symptoms such as gastrointestinal abnormalities, diarrhea, vomiting, abdominal pain and nausea (15). Reduction in blood flow toward splanchnic organs during exercise has been suggested as the reason for these complications (16). Rowel et al (17) showed that the blood flow of splanchnic organs in human beings is reduced during exercise $\left(\% 70 \mathrm{VO}_{2 \max }\right)$. Thereafter, Qamar and Read (18) documented a reduction in intestinal blood flow during exercise where each patient walked for $15 \mathrm{~min}$ at $5 \mathrm{~km} / \mathrm{h}$ up a $20 \%$-inclined platform. Also this effect of exercise has been demonstrated by Musch et al in dogs (19) and old rats (20). Short 
periods of ischemia can induce tolerance to subsequent long-term $\mathrm{I} / \mathrm{R}$. This phenomenon is termed as ischemic preconditioning (IPC). A question arises as to whether gastrointestinal ischemia occuring during exercise may be a model of ischemic-preconditioning for subsequent long-term ischemia.

The aim of the present study was to investigate the protective effects of exercise preconditioning against intestinal $\mathrm{I} / \mathrm{R}$ injury in a rat model.

\section{Materials and methods}

Four-month-old male Wistar-Albino rats were used in this study. The weights of the animals ranged between 280 and 300 g. Animals were housed at constant temperature $\left(20-22{ }^{\circ} \mathrm{C}\right)$ and humidity (50-60\%) under a 12-h light/12-h dark cycle. During the experiment, each rat had free access to standard food pellets and water. The animals received care according to NIH Guide for The Care and Use of Laboratory Animals, and the study protocol was approved by the Institutional Animal Care and Use Committee.

\section{Animal and groups}

Sixty rats were randomly divided into six groups as sham (n $=10)$, ischemia-reperfusion $(\mathrm{I} / \mathrm{R})(\mathrm{n}=10)$, exercise $(\mathrm{E})(\mathrm{n}=10)$, exercise plus ischemia-reperfusion $(\mathrm{E}+\mathrm{I} / \mathrm{R})(\mathrm{n}=10)$, ischemic preconditioning (IPC) $(\mathrm{n}=10)$, and ischemic preconditioning plus ischemia-reperfusion (IPC+I/R) $(n=10)$ groups. Rats were exposed to laparotomy without clamping the superior mesenteric artery (SMA) in the sham group. Rats were exposed to laparotomy with occlusion of SMA for $45 \mathrm{~min}$, followed by $120 \mathrm{~min}$ of reperfusion period in the I/R group. Rats in the E group were exposed to treadmill exercise ( $25 \mathrm{~m} / \mathrm{min}, 45 \mathrm{~min} /$ day for 4 weeks), and $24 \mathrm{~h}$ after the last exercise session, animals were exposed to laparotomy. Rats in the E+I/R group performed treadmill exercise $(25 \mathrm{~m} / \mathrm{min}$, $45 \mathrm{~min} /$ day for 4 weeks) and $24 \mathrm{~h}$ after the last exercise session, they were subjected to I/R procedure, as in I/R group. Rats were exposed to laparotomy with clamping of SMA for $10 \mathrm{~min}$ followed by $10-$ min reperfusion in the IPC group. Rats in the IPC $+\mathrm{I} / \mathrm{R}$ group were exposed to laparotomy with clamping of SMA for $10 \mathrm{~min}$ followed by $10 \mathrm{~min}$ of reperfusion followed by I/R (as in I/R group).

\section{Exercise training protocol}

Animals in the trained groups were exposed to motorized treadmill test (MAY TME 9805 Treadmill Exerciser, Commat Iletisim Ltd., Ankara, Turkey) and preconditioned for a total of five days by forcing them to run at a speed of $10 \mathrm{~m} \mathrm{x} \mathrm{min}^{-1}$ for $10 \mathrm{~min}$ on the first day up to $25 \mathrm{~m} \mathrm{x} \mathrm{min}^{-1}$ on the fifth day. After two days of rest, animals in exercise groups were exposed to five sessions of treadmill exercise at speed of $25 \mathrm{~m} / \mathrm{min}$ for $45 \mathrm{~min} \mathrm{x} \mathrm{day}^{-1}$ per week for a total of four weeks on a horizontal ( $0 \%$ inclination) platform. Trained rats were subjected to $\mathrm{I} / \mathrm{R}$ or sham procedure $24 \mathrm{~h}$ after the last training session.

\section{Surgery}

Rats were fasted for 12 hours with free access to water before operation. Animals were anesthetized by intraperitoneal injection of ketamine hydrochloride plus xylazine $(50-10 \mathrm{mg} / \mathrm{g})$. The abdomen was opened with a midline incision. The intestinal I/R injury was established by occluding SMA with atraumatic microvascular clip for 45 min followed by 120-min reperfusion. Ischemia was recognized by the lack of pulse or pale color of the intestines. Following induction of ischemia, microvascular clamp was removed and the presence of reperfusion was confirmed by restoration of pulsation and pinky color prior to closing the incision. Abdomens of sham operated rats were incised without exposing them to I/R injury. SMAs of ischemic preconditioned rats were clamped for $10 \mathrm{~min}$, which was followed by $10 \mathrm{~min}$ reperfusion after laparotomy. At the end of the experiment, blood samples were taken with cardiac puncture for the measurement of serum concentrations of TNF- $\alpha$ and IL-6. All animals were sacrificed by cervical dislocation. Small intestinal segments were retrieved for the determination of malondialdehyde (MDA) levels, and activities of superoxide dismutase (SOD) and myeloperoxidase (MPO) after sacrification. All samples were immediately frozen and stored at $-80^{\circ} \mathrm{C}$ for biochemical analyses.

\section{Biochemical analysis}

All tissues were washed with ice cold saline solution and homogenized in 10 volumes of ice-cold Tris-HCL buffer $(50 \mathrm{mmol} / \mathrm{L}$, pH 7.4) using a homogenizer (Wise Mix HG-15; Daihan Scientific, Seoul, Korea) after cutting the tissue into small pieces. MDA levels, and MPO and SOD activities were determined in this homogenate. Also some of the homogenate was centrifuged and supernatants were separated. The supernatant solution was extracted with an equal volume of an ethanol/chloroform mixture (5/3, volume per volume $[\mathrm{v} / \mathrm{v}])$. After centrifugation at $5000 \mathrm{~g}$ for $30 \mathrm{~min}$, the upper layer (ethanol phase) was used in protein assays. The protein content of tissue homogenates was measured by the method of Lowry et al (21).

Lipid peroxidation in the tissues was assessed by the TBARS method using a commercially available kit according to the manufacturer's instructions and MDA as a standard (TBARS kit; Cayman Chemical Co. Michigan, USA). Absorbance was measured at $530 \mathrm{~nm}$. MDA levels were expressed as $\mathrm{nmol} / \mathrm{g}$ of wet tissue. Activity of MPO, a marker of tissue leukocyte infiltration, was determined in intestinal tissues with a colorimetric assay using a rat MPO ELISA kit according to the manufacturer's instructions (Hycult Biotechnology, Uden, Netherlands). MPO activities of the samples were measured at $450 \mathrm{~nm}$ (Powewave XS, Biotek, USA), and the concentrations were standardized per amount of protein in tissue. For determination of SOD activity, a commercially available SOD assay kit (Cayman Chemical, Ann Arbor, MI, USA) was used. The kit utilizes tetrazolium salt for the detection of superoxide radicals generated by xanthine oxidase and hypoxanthine. The reactions were initiated by adding xanthine oxidase to the test solution, and incubating it for $20 \mathrm{~min}$ at room temperature. Afterwards absorbance was read at $450 \mathrm{~nm}$. One unit of SOD activity was defined as the amount of enzyme needed to inhibit 50\% dismutation of the superoxide radical. Data were expressed as U/mg protein.

Serum samples were assayed for proinflammatory cytokine levels (IL-6 and TNF- $\alpha$ ) using an enzyme-linked immunosorbent 
assay (ELISA). Cytokine assays were performed as described by the manufacturer's protocol (Bender Med systems Diagnostics, Vienna, Austria). The relationship between optical density and cytokine concentrations was defined using the standard curve according to the manufacturer's instructions. IL- 6 and TNF- $\alpha$ levels are expressed as $\mathrm{pg} / \mathrm{ml}$.

\section{Histopathological analysis}

A section of distal ileum from all rats was removed and fixed in $10 \%$ formalin solution. Afterwards the samples were embedded in paraffin and cut into 5- $\mu \mathrm{m}$ sections. Paraffin sections were then stained with hematoxylin and eosin (HE). Tissue injury in the intestinal mucosa was evaluated under a light microscope according to the criteria described by Chiu et al (22) and graded from 0 to $8(0=$ normal mucosa; $1=$ subepithelial Gruenhagens space, capillary congestion; $2=$ extension of the subepithelial space with moderate lifting of the epithelial layer from lamina propria; $3=$ massive epithelial lifting down the sides of villi, few tips denuded; $4=$ denuded villi with lamina propria, dilated capillaries exposed; $5=$ digestion and disintegration of lamina propria, hemorrhage, ulceration; $6=$ cyrpt layer injury hemorrhage; $7=$ transmucosal infarction; $8=$ transmural infarction).

\section{Statistical analysis}

Data analysis was performed by using SPSS for Windows, version 11.5 (SPSS Inc., Chicago, IL, US). All results are presented as means \pm SD. Differences among the groups were analyzed by the Kruskal-Wallis test. Pairwise comparisons between groups presenting significant values were evaluated with Mann-Whitney $\mathrm{U}$ test. Histopathologic grades of the groups were compared with one-way ANOVA and Tukey HSD test. Value of $p$ less than 0.05 was considered statistically significant.

\section{Results}

Serum TNF- $\alpha$ and IL- 6 levels of the groups are presented in Table 1. Serum TNF- $\alpha$ levels were lower in E and IPC groups compared to the sham group $(\mathrm{p}<0.05)$, and higher in $\mathrm{E}+\mathrm{I} / \mathrm{R}$ group compared to E group $(\mathrm{p}<0.05)$. IL-6 levels were not different among groups.

Small intestinal tissue MDA levels and MPO and SOD activities are shown in Table 2. Intestinal I/R produced a significant increase in MPO activity as compared with the sham group ( $\mathrm{p}<$ $0.05)$. MPO activity was significantly lower in $\mathrm{E}$ and IPC groups compared to $\mathrm{I} / \mathrm{R}$ group $(\mathrm{p}<0.05)$. In $\mathrm{E}+\mathrm{I} / \mathrm{R}$ group, MPO activity was higher compared to sham and E groups $(p<0.05)$. In IPC group, MPO activity was lower compared to $\mathrm{E}+\mathrm{I} / \mathrm{R}$ group $(\mathrm{p}<$ $0.05)$. MDA levels were not different among the groups. SOD activity was significantly lower in I/R group compared to sham group $(\mathrm{p}<0.05)$. SOD activity in IPC and IPC $+\mathrm{I} / \mathrm{R}$ groups were significantly higher compared to $\mathrm{I} / \mathrm{R}$ and $\mathrm{E}$ groups, respectively $(\mathrm{p}<0.05)$.

Normal non-ischemic ileal tissue was seen in the sham group (Fig. 1A). The damage in I/R group was found to be increased compared with the sham group (Fig. 1B) $(\mathrm{p}<0.05)$. The median intestinal mucosal injury score in $\mathrm{E}+\mathrm{I} / \mathrm{R}$ group was significantly lower relative to I/R group, but significantly higher when compared with the sham group (Tab. 3) $(\mathrm{p}<0.05)$.

\section{Discussion}

To our knowledge, this is the first report investigating the effects of exercise preconditioning on oxidative stress and antioxidant status in intestinal $I / R$ injury induced in rats. The results of the present study indicate that exercise training seems to have a protective role against intestinal I/R injury.

Table 1. Serum TNF- $\alpha$ and IL-6 levels in the study groups (mean \pm SD).

\begin{tabular}{lcccccc}
\hline & $\begin{array}{c}\text { Sham Group } \\
(\mathrm{n}=10)\end{array}$ & $\begin{array}{c}\text { Group I/R } \\
(\mathrm{n}=10)\end{array}$ & $\begin{array}{c}\text { Group E } \\
(\mathrm{n}=10)\end{array}$ & $\begin{array}{c}\text { Group E+I/R } \\
(\mathrm{n}=10)\end{array}$ & $\begin{array}{c}\text { Group IPC } \\
(\mathrm{n}=10)\end{array}$ & $\begin{array}{c}\text { Group IPC+I/R } \\
(\mathrm{n}=10)\end{array}$ \\
\hline TNF- $\alpha(\mathrm{pg} / \mathrm{ml})$ & $154.26 \pm 6.23$ & $147.94 \pm 13.62$ & $141.98 \pm 6.49^{\mathrm{a}}$ & $150.16 \pm 5.08^{\mathrm{b}}$ & $147.22 \pm 7.77 \mathrm{a}$ & $149.13 \pm 11.99$ \\
IL-6 $(\mathrm{pg} / \mathrm{ml})$ & $311.83 \pm 124.22$ & $483.50 \pm 148.70$ & $326.63 \pm 152.01$ & $381.63 \pm 171.17$ & $367.79 \pm 147.66$ & $321.75 \pm 146.04$ \\
\hline
\end{tabular}

$\mathrm{I} / \mathrm{R}=$ Ischemia-reperfusion; $\mathrm{E}=$ Exercise; IPC= Ischemic-preconditioning.

${ }^{a}=p<0.05$ versus Sham; ${ }^{b}=p<0.05$ versus $E$.

Table 2. The oxidant and antioxidant tissue parameters of the study groups (mean $\pm \mathrm{SD}$ ).

\begin{tabular}{|c|c|c|c|c|c|c|}
\hline & $\begin{array}{l}\text { Sham Group } \\
(n=10)\end{array}$ & $\begin{array}{c}\text { Group I/R } \\
(\mathrm{n}=10)\end{array}$ & $\begin{array}{c}\text { Group E } \\
(\mathrm{n}=10)\end{array}$ & $\begin{array}{c}\text { Group } E+I / R \\
(n=10)\end{array}$ & $\begin{array}{l}\text { Group IPC } \\
(n=10)\end{array}$ & $\begin{array}{c}\text { Group IPC+I/R } \\
(\mathrm{n}=10)\end{array}$ \\
\hline MDA (nmol/g tissue) & $2.85 \pm 0.30$ & $2.80 \pm 0.28$ & $2.62 \pm 0.19$ & $2.65 \pm 0.24$ & $2.69 \pm 0.14$ & $2.91 \pm 0.39$ \\
\hline MPO (ng/mg protein) & $280.54 \pm 50.20$ & $363.20 \pm 67.74^{\mathrm{a}}$ & $276.98 \pm 69.00^{\mathrm{b}}$ & $334.34 \pm 51.68^{\mathrm{a}, \mathrm{c}}$ & $278.11 \pm 44.73^{\mathrm{b}, \mathrm{d}}$ & $341.38 \pm 85.05$ \\
\hline SOD (U/mg protein) & $1.63 \pm 0.48$ & $0.61 \pm 0.35^{\mathrm{a}}$ & $1.28 \pm 0.79$ & $1.05 \pm 0.85$ & $1.68 \pm 0.72^{\mathrm{b}}$ & $1.75 \pm 0.58^{\mathrm{e}}$ \\
\hline
\end{tabular}

$\mathrm{MDA}=$ Malonyldialdehyde; $\mathrm{MPO}=$ Myeloperoxidase; $\mathrm{SOD}=$ Superoxide dismutase; $\mathrm{I} / \mathrm{R}=$ Ischemia-reperfusion; $\mathrm{E}=\mathrm{Exercise} ; \mathrm{IPC}=\mathrm{Ischemic}-\mathrm{preconditioning}$

${ }^{a}=p<0.05$ versus Sham $;^{b}=p<0.05$ versus $I / R ;{ }^{c}=p<0.05$ versus $E ;{ }^{d}=p<0.05$ versus $E+I / R ;{ }^{e}=p<0.001$ versus $I / R$.

Table 3. The effects of exercise on intestinal tissue injury index after ischemia-reperfusion (mean $\pm \mathrm{SD})$.

\begin{tabular}{lccccc}
\hline & $\begin{array}{c}\text { Sham Group } \\
(\mathrm{n}=10)\end{array}$ & $\begin{array}{c}\text { Group I/R } \\
(\mathrm{n}=10)\end{array}$ & $\begin{array}{c}\text { Group E } \\
(\mathrm{n}=10)\end{array}$ & $\begin{array}{c}\text { Group E+I/R } \\
(\mathrm{n}=10)\end{array}$ & $\begin{array}{c}\text { Group IPC } \\
(\mathrm{n}=10)\end{array}$ \\
ITII & $0.00 \pm 0.00$ & $3.75 \pm 0.46^{\mathrm{a}}$ & $0.25 \pm 0.46^{\mathrm{a}, \mathrm{b}}$ & $2.63 \pm 0.52^{\mathrm{a}, \mathrm{b}}$ & $\begin{array}{c}\text { Group IPC+I/R } \\
(\mathrm{n}=10)\end{array}$ \\
\hline
\end{tabular}

ITII= Intestinal tissue injury index; I/R= Ischemia-reperfusion; E= Exercise; IPC = Ischemic-preconditioning

${ }^{a}=p<0.05$ versus Sham; ${ }^{b}=p<0.05$ versus I/R; ${ }^{c}=p<0.05$ versus $E ;{ }^{d}=p<0.05$ versus IPC. 

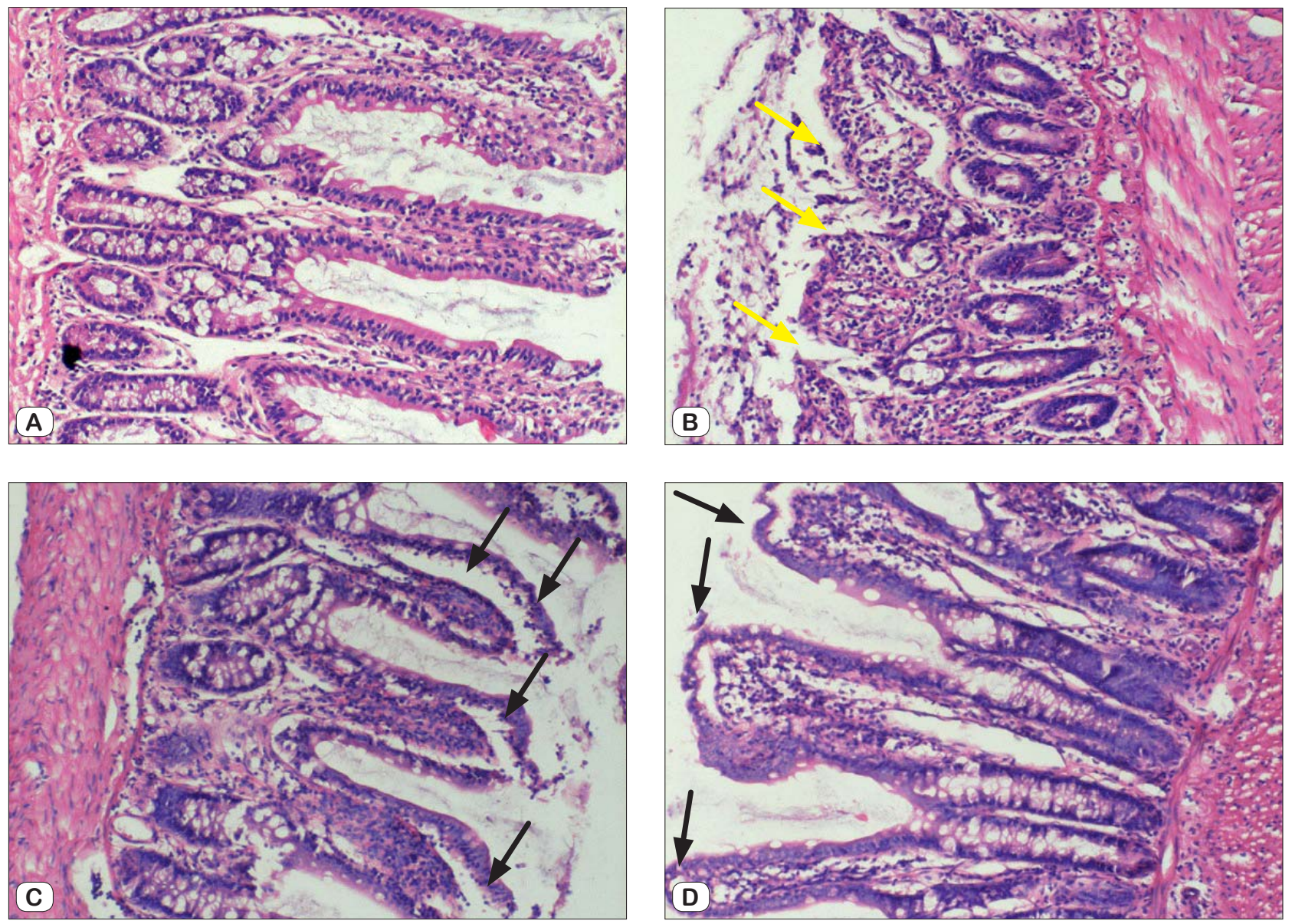

Fig. 1. The microscopic appearance of the mucosal changes. $A=$ Normal intestinal epithelium and villi (Grade 0$)$. $B=$ Several areas of mucosal damage in the I/R group (Grade 4). $\mathrm{C}=$ Ischemia reperfusion treated with ischemic preconditioning (Grade 3). $\mathrm{D}=$ Moderate mucosal damage (Grade 2) in the $\mathbf{E}+\mathbf{I} / \mathbf{R}$ group. Histopathological features of ileum in association with ischemia-reperfusion were characterized by necrosis of the mucosa (haematoxylin and eosin $\mathbf{x 1 0 0 )}$.

Physical activity is considered beneficial for preventing ischemic heart disease as well as for decreasing the cardiovascular mortality (12). There is also increasing evidence that physical activity is associated with a decreased incidence of stroke (23). A previous study by Quindry et al (24) showed that exercise protects heart against myocardial ischemia induced by an increase in antioxidant capacity in rats. However, it is well known that during an exercise session, blood flow to the splachnic region is greatly reduced because of its deviation to active skeletal musculature and skin (20). For protection of tissues from I/R injury, defensive mechanisms such as IPC has been developed. IPC refers to one or more short periods of ischemia before prolonged I/R. It protects tissues from injury-induced I/R. It has been shown that ischemic preconditioning can protect organs against $\mathrm{I} / \mathrm{R}$ injury both in cardiac and intestinal tissues (25--27). De Lira et al (28) suggested that their exercise protocol (multiple sessions at 60-min ischemia/24-h reperfusion for 10-25-40 and 50 days) can be classified as having lower intensity than the one triggered by a unique acute mesenteric artery occlusion. In this instance, the effect of exercise against gastrointestinal I/R injury is biphasic. Exercise may increase antioxidant levels in tissues (24). Afterwards, exercise session (s) can induce effects of ischemic-preconditioning on gastrointestinal tissues (28).

The intestinal tissue is known to be highly sensitive to I/R. Oxidative stress plays a crucial role in intestinal I/R injury. During $I / R$, several events take place. Activated neutrophils induce tissue damage through the production and release of reactive oxygen species and cytotoxic proteins such as MPO into extracellular fluid. In this stage of the inflammatory cascades, the radical-induced $\mathrm{I} / \mathrm{R}$ injury is activated (1). MPO activity is a reliable index of tissue-associated polymorphonuclear leukocyte accumulation in ileal tissue of I/R rats. In the present study, MPO activity of the intestinal tissue was significantly higher in the $\mathrm{I} / \mathrm{R}$ group when compared to the sham group. These findings indicated that $120-$ min reperfusion after 45-min ischemia period was sufficient to induce $\mathrm{I} / \mathrm{R}$ injury in rats.

During ischemia-reperfusion injury, proinflammatory cytokines such as TNF- $\alpha$, IL-1 and IL- 6 are released by macrophages (29). The induction of systemic proinflammatory cytokine response may be an important contributor to the pathophysiology of $I / R$ 
injury. However, endurance exercise caused a decrease in serum TNF- $\alpha$ level (30). In the present study, a significant reduction in the serum TNF- $\alpha$ level was observed after 4 weeks of exercise training in rats $(\mathrm{p}<0.05)$. In the $\mathrm{E}+\mathrm{I} / \mathrm{R}$ group, TNF- $\alpha$ level was found to be significantly increased when compared with sham group, which demonstrated that the ischemia protocol was succesful.

Oxygenation of ischemic tissues during reperfusion aggravates the intestinal injury due to the formation of reactive oxygen species (4). Increased concentrations of MDA indicate a degree of lipid peroxidation confirming the oxidative damage in intestinal tissues. In experimental studies with I/R models (29, 31, 32), MDA levels in intestinal tissue were found to be significantly higher in $\mathrm{I} / \mathrm{R}$ group compared to sham and treatment groups. A prior study (28) also showed that the MDA level in intestinal tissues in rats subjected to exercise tests was significantly lower than that in sham group. However in our study, there was no significant difference among MDA levels in rats. In consistency with our findings, it has been reported that the MDA levels of ileum tissue were not altered by intestinal I/R in mice (33). The unchanged MPO levels in the present study may depend on the analysis method. It is a common knowledge, but largely ignored, that neither the BARS assay that we used is specific to MDA, nor the lipid peroxidation is the only source of MDA (34). Nevertheless, these methodological problems occur in analytical procedures in some studies.

As a first step, SOD detoxifies the superoxide anion to hydrogen peroxide (35). The intestinal I/R injury was associated with dramatic increases in MDA level and MPO activity and decrease in SOD activity (31). In the present study, SOD activity in the I/R group was significantly lower than in the sham group $(\mathrm{p}<0.05)$. SOD activity in IPC $+\mathrm{I} / \mathrm{R}$ group was significantly higher than in I/R group. The protective effect of exercise against I/R injury has been investigated in several studies $(23,24,30)$. The mechanisms of action of exercise on I/R injury are not clearly understood. Although there are many mechanisms suggested, the most important one is related to increased levels of antioxidants in tissues (24). In consistency with the previous study, SOD activity in our study was found to be significantly lower in I/R group compared to the sham group (31). The activity of SOD was increased in rats that had been exposed to exercise tests for four weeks but this increase had no statistical meaning. Gastrointestinal blood flow decreases during exercise (20). Moses suggested that the reason for gastrointestinal symptoms during exercise can lie in gastrointestinal ischemia (16). Moreover, de Lira et al (28) suggested that ischemia during exercise in gastrointestinal tissues may have a similar effect just as SMA occlusion. This may mean that ischemia during exercise results in ischemic-preconditioning. In our study, SOD activity of IPC + I/R group was significantly higher than that of $\mathrm{I} / \mathrm{R}$ group. The ischemic preconditioning protects intestinal tissue against I/R injury by increasing the SOD activity. Our exercise protocol did not cause any significant alteration in the activity of SOD in ileal tissues in $\mathrm{E}+\mathrm{I} / \mathrm{R}$ group compared with I/R group. This may depend on the intensity of exercise. In addition, in exercised group, MPO activities and MDA levels did not change after I/R. However, histopathological examination showed that exercise attenuated the degree of ischemia in ileal tissue after
I/R. Our findings exhibit that the protection mechanism of exercise preconditioning against intestinal I/R injury is not associated with altered MDA levels and MPO and SOD activities and also partially with IPC.

In conclusion, to our knowledge, this is the first report demonstrating the effect of exercise preconditioning on intestinal I/R. Endurance exercise has a potential protective effect against intestinal $\mathrm{I} / \mathrm{R}$ injury, although further studies are needed to clarify the role of exercise preconditioning regarding the prevention of intestinal I/R injury and also to observe the effects of different exercise protocols.

\section{References}

1. Mallick IH, Yang W, Winslet MC, Seifalian AM. Ischemia-reperfusion injury of the intestine and protective strategies against injury. Dig Dis Sci 2004; 49: 1359-1377.

2. Schoenberg MH, Beger HG. Reperfusion injury after intestinal ischemia. Crit Care Med 1993; 21: 1976-1986.

3. Riaz AA, Wan MX, Schäfer T et al. Allopurinol and superoide dismutase protect against leucocyte-endothelium interactions in a novel model of colonic ischemia-reperfusion. Br J Surg 2002; 89: 1572-1580.

4. Granger DN, Höllwarth ME, Parks DA. Ischemia-reperfusion injury: role of oxygen-derived free radicals. Acta Physiol Scand Suppl. 1986; 548: 47-63.

5. Kaszaki J, Wolfárd A, Szalay L, Boros M. Pathophysiology of ischemia-reperfusion injury. Transplant Proc 2006; 38: 826-828.

6. Offord E, van Poppel G, Tyrrell R. Markers of oxidative damage and antioxidant protection: current status and relevance to disease. Free Radic Res. 2000; 33: 5-19.

7. Simpson R, Alon R, Kobzik L et al. Neutrophil and non neutrophilmediated injury in intestinal ischemia-reperfusion. Ann Surg 1993; 218 : 444-453.

8. Rock P, Yao Z. Ischemia reperfusion injury, preconditioning and critical illness. Curr Opin Anaesthesiol 2002; 15: 139-146.

9. Lee IM, Hennekens CH, Berger $\mathrm{K}$ et al. Exercise and risk of stroke in male physicians. Stroke 1999; 30: 1-6.

10. Hu FB, Stampfer MJ, Colditz GA et al. Physical activity and risk of stroke in women. JAMA 2000; 283: 2961-2967.

11. Blair Sn, Cheng Y, Holder JS. Is physical activity or physical fitness more important in defining health benefits. Med Sci Sports Exerc 2001; 33: 379-399.

12. Roberts CK, Barnard RJ. Effets of exercise and diet on chronic disease. J Appl Physiol 2005; 98: 3-30.

13. Powers SK, Demirel HA, Vincent HK et al. Exercise training improves myocardial tolerance to in vivo ischemia-reperfusion in the rat. Am J Physiol 1998; 275: 1468-1477.

14. Demirel HA, Powers SK, Caillaud C et al. Exercise training reduces myocardial lipid peroxidation following short-term ischemia-reperfusion. Med Sci Sports Exerc 1998; 30: 1211-1216.

15. Simren M. Physical activity and the gastrointestinal tract. Eur J Gastroenterol Hepatol 2002; 14: 1053-1056.

16. Moses FM. Exercise- associated intestinal ischemia. Curr Sports Med Rep 2005; 4: 91-95. 
17. Rowel LB, Blackmon JR, Bruce RA. Indocyanine gren clearance and estimated hepatic blood flow during mild to maximal exercise in upright man. J Clin Invest 1964; 43: 1677-1690.

18. Qamar MI, Read AE. Effects of exercise on mesenteric blood flow in man. Gut 1987; 28: 583-587.

19. Musch TI, Friedman DB, Pitetti KH et al. Regional distribution of blood flow of dogs during graded dynamic exercise. J Appl Physiol 1987; 63: 2269-2277.

20. Musch TI, Eklund KE, Hageman KS, Poole DC. Altered regional blood flow responses to submaximal exercise in older rats. J Appl Physiol 2004; 96: 81-88.

21. Lowry OH, Risebrough NJ, Farr AL, Randal RJ. Protein measurement with folin phenol reagent. J Biol Chem. 1951; 193: 265-275.

22. Chiu CJ, McArdle AH, Brown R, Scott HJ, Gurd FN. Intestinal mucosal lesion in low-flow states: a morphological, hemodynamic and metabolic reappraisal. Arch Surg 1970; 101: 478-483.

23. Ding $\mathbf{Y}, \mathbf{L i} \mathbf{J}$, Luan $\mathrm{X}$ et al. Exercise pre-conditioning reduces brain damage in ischemic rats thatmay be associated with regional angiogenesis and cellular overexpression of neurotrophin. Neuroscience 2004; 124 : 583-591.

24. Quindry J, French J, Hamilton $\mathbf{K}$ et al. Exercise training provides cardioprotection against ischemia-reperfusion induced apoptosis in young and old animals. Exp Gerontol 2005; 40: 416-425.

25. Murry CE, Jennings RB, Reimer KA. Preconditioning with ischemia: a delay of lethal cell injury in ischemic myocardium. Circulation 1986; 74: 1124-1136.

26. Siler P, Sica G, Gentileschi P et al. Ischemic preconditioning protects intestine from prolonged ischemia. Transplant Proc 2004; 36: 283-285.
27. Takeshita M, Tani T, Harada S et al. Role of transcription factors in small intestinal ischemia-reperfusion injury and tolerance induced by ischemic preconditioning. Transplant Proc 2010; 42: 3406-3413.

28. de Lira CA, Vancini RL, Ihara SS et al. Aerobic exercise affects C57BL/6 murine intestinal contractile function. Eur J Appl Physiol 2008; 103: 215-223.

29. Hajipour B, Somi MH, Saberifar F et al. Simvastatin attenuates intestinal ischemia/reperfusion induced injury in rat. Folia Morphol (Warsz) 2009; 68: 156-162.

30. Mussi RK, Camargo EA, Ferreira T et al. Exercise training reduces pulmonary ischemia-reperfusion-induced inflammatory responses. Eur Respir J 2008; 31: 645-64.

31. Liu KX, Rinne T, He W et al. Propofol attenuates intestinal mucosa injury induced by intestinal ischemia-reperfusion in the rat. Can J Anaesth 2007; 54: 366-374.

32. Zhang W, Zhu W, Zhang J et al. Protective effects of glukagon-like peptide 2 on intestinal ischemia-reperfusion rats. Microsurgery 2008; 28: 285-290.

33. Barocelli E, Ballabeni V, Ghizzardi P, Cattaruzza F et al. The selective inhibition of induible nitric oxide synthase prevents intestinal ischemia-reperfusion injury in mice. Nitric Oxide 2006; 14: 212-218.

34. Vollaard NB, Shearman JP, Cooper CE. Exercise-induced oxidative stres: myths, realities and physiological relevance. Sports Med 2005; 35: 1045-1062.

35. Yildiz Y, Serter M, Ek RO et al. Protective effects of caffeic acid phenethyl ester on intestinal ischemia-reperfusion injury. Dig Dis Sci 2009; 54: 738-744. 